\title{
Spatiotemporal differentiation of changes in maize phenology in China from 1981 to 2010
}

\author{
LIU Yujie ${ }^{1,3}$, QIN Ya ${ }^{1,2}$, GE Quansheng ${ }^{1,3}$
}

1. Key Laboratory of Land Surface Pattern and Simulation, Institute of Geographic Sciences and Natural Resources Research, CAS, Beijing 100101, China;

2. College of Surveying and Mapping Science and Technology, Xi'an University of Science and Technology, Xi'an 710054, China;

3. University of Chinese Academy of Sciences, Beijing 100049, China

\begin{abstract}
Spatio-temporal changes in the differentiation characteristics of eight consecutive phenological periods and their corresponding lengths were quantitatively analyzed based on long-term phenological observation data from 114 agro-meteorological stations in four maize growing zones in China. Results showed that average air temperature and growing degree-days (GDD) during maize growing seasons showed an increasing trend from 1981 to 2010 , while precipitation and sunshine duration showed a decreasing trend. Maize phenology has significantly changed under climate change: spring maize phenology was mainly advanced, especially in northwest and southwest maize zones, while summer and spring-summer maize phenology was delayed. The delay trend observed for summer maize in the northwest maize zone was more pronounced than in the Huang-Huai spring-summer maize zone. Variations in maize phenology changed the corresponding growth stages length: the vegetative growth period (days from sowing date to tasseling date) was generally shortened in spring, summer, and spring-summer maize, although to different degrees, while the reproductive growth period (days from tasseling date to mature date) showed an extension trend. The entire growth period (days from sowing date to mature date) of spring maize was extended, but the entire growth periods of summer and spring-summer maize were shortened.
\end{abstract}

Keywords: maize; phenology; climate change; spatio-temporal differentiation; China

\section{Introduction}

Phenology can intuitively indicate changes in seasons and climate (Zheng et al., 2012; He et al., 2015), thus being an important biological indicator for measuring regional climate change. According to the Fifth Assessment Report of the Intergovernmental Panel on Climate Change (IPCC, 2014), the average global surface temperature has increased by $0.89^{\circ} \mathrm{C}$

Received: 2018-01-15 Accepted: 2018-07-12

Foundation: National Natural Science Foundation of China, No.41671037; Youth Innovation Promotion Association of CAS, No.2016049; Key Research Program of Frontier Sciences, CAS, No.QYZDB-SSW-DQC005; Program for "Kezhen" Excellent Talents in IGSNRR, CAS, No.2017RC101

"Corresponding author: Liu Yujie, PhD and Associate Professor, specialized in climate change. E-mail: liuyujie@igsnrr.ac.cn 
from 1901 to 2012. An increase in air temperature can promote enzyme activity and accelerate the phenological processes of plants, thus shortening plant growing seasons. In turn, changes in the length of plant growing seasons can modify vegetation productivity and structural composition, as well as water, heat, and carbon exchange rates in the soil-vegetation-atmosphere system, thereby affecting the climate system and exacerbating climate change (Wang et al., 2015; Cui et al., 2018). As agricultural production is directly affected by climate change (Guo, 2015), studying the patterns of phenological changes in crops is of great importance for guiding regional agricultural production and mitigating the negative impacts of climate change.

Under the scenario of climate change, maize phenology has been examined worldwide. Based on the Agro-IBIS model (a process-based ecosystem model adapted from the Integrated Biosphere Simulator), Sacks and Kucharik (2011) found that the sowing date and maturity date of maize advanced 0.40 day per year and delayed 0.10 day per year, respectively, between 1981 and 2005 in the US Corn Belt. Chinese scholars have found that, due to climate warming, the tasseling date and maturity date at more than $80 \%$ of the country's maize production sites advanced by an average of 3.2 days and 6.0 days, respectively, over each 10-year period (Tao et al., 2014). In northeast China, the sowing date of maize advanced and the maturity date delayed by 4-21 days from 1981 to 2007 (Liu et al., 2013). In Inner Mongolia, the sowing date and maturity date of maize advanced by 1.0 day and delayed by 3.3 days per 10-year period, respectively, from 1981 to 2009 (Xiao, 2015). Fu et al. (2016) conducted temperature increment experiments in Tibet Autonomous Region and found that air temperature increments generally led to advancing trends in the phenological phases of maize to different degrees. Under the influence of increasing average air temperature, decreased precipitation with increased latitude, and substantial decline in sunshine duration, the seeding, jointing, and silking dates of summer maize in Jing-Jin-Ji (Beijing-Tianjin-Hebei) region and Shandong Province were significantly delayed, and the seeding, jointing, and silking dates of summer maize in Henan Province advanced considerably (Meng et al., 2015).

Based on the above results, previous studies mainly focused on the effect of air temperature increase on maize phenological phases in the context of climate change. In addition to temperature, moisture and sunshine duration can also affect crop growth (Liu et al., 2018a). For example, shortened sunshine duration can promote flowering of short-day plants and advance their flowering stage, while extended sunshine duration delays the flowering stage. Zheng et al. (2002) found that the main factor influencing flowering in winter and early spring plants is air temperature, whereas the flowering of late spring and early summer plants is simultaneously affected by air temperature and sunshine duration; the onset of pollen spreading in late summer plants is mainly affected by sunshine duration. Under certain sunshine conditions, changes in air relative humidity can also cause changes in plant phenology (Wang et al., 2010). In addition, limited by observation data and model simulation capabilities, studies conducted so far have mostly focused on individual key phenological phases, such as seeding, tasseling, and ripening dates, and lack a systematic analysis on the changing patterns of multiple phenological phases during crop growth. Moreover, due to the influence of local and regional climates, the same phenological stages of the same crop significantly differ among different regions, and most studies have been conducted at the 
regional scale or include only a few sites. For example, Zhao et al. (2015) explored the effects of sowing date adjustment and species change on maize growing season and yield in five maize production sites in northeast China (two in Heilongjiang, two in Jilin, and one in Liaoning). Wang et al. (2015) selected three to four representative sites in northeast, north, and southwest China to examine the uncertain factors in model simulation of maize phenology. The growth process of maize is influenced by multiple climate factors, but changes in the patterns of multiple consecutive phenological stages, especially changes in the trends of spatial differentiation patterns for each phenological stage during maize growth, hence further examination is still needed.

Therefore, based on long-term observation data (1981 to 2010) from 114 agro-meteorological stations in the four major maize growing zones in China, this study aims to: (1) quantify spatial and temporal changes occurring in the differentiation characteristics of maize regarding sowing, seedling, three-leaf, seven-leaf, jointing, tasseling, milk-ripe, and ripening dates; and (2) examine the changes in the patterns of the phenological phases and length of growing seasons for different planting types of maize in different regions in the context of changes in key climate factors (average air temperature, precipitation, and sunshine duration). The results obtained here could provide a theoretical reference for regional agricultural production practices.

\section{Data and methods}

\subsection{Data}

This study examined spring, summer, and spring-summer maize grown in the northwest maize zone, northern spring maize zone, Huang-Huai spring-summer maize zone, and southwest maize zone, which are the four main maize production zones in China, based on the Chinese maize planting zonations (Tong, 1992). The sowing date of spring maize is from late April to early May, and that of summer maize is from early June to mid-July. Spring-summer maize is sowed at intervals between April and June or between May and June, and its sowing date is mainly affected by the planting time of the previous seasonal crops.

The research sites selected for the present study met the following four criteria: (1) typical site and representative of the agricultural production status of local maize; (2) with long-term (1981-2010) maize phenological observation data; (3) with meteorological observation station; and (4) with field management records, including information on maize variety, irrigation, and fertilization, among other features. According to data quality, 114 sites with complete observation records were selected (Figure 1). These sites were distributed in the northwest maize zone (17 sites), northern spring maize zone (54 sites), Huang-Huai spring-summer maize zone (32 sites), and southwest maize zone (11 sites). Maize growth season was divided into three key growth stages: vegetative growth stage (sowing to tasseling date), reproductive growth stage (tasseling to ripening date), and the entire growth stage (sowing to ripening date). The lengths of these three growth stages were calculated separately. Climate data for the 114 sites during the 1981-2010 period were obtained from the data sharing website (http://data.cma.cn/site/index.html). 


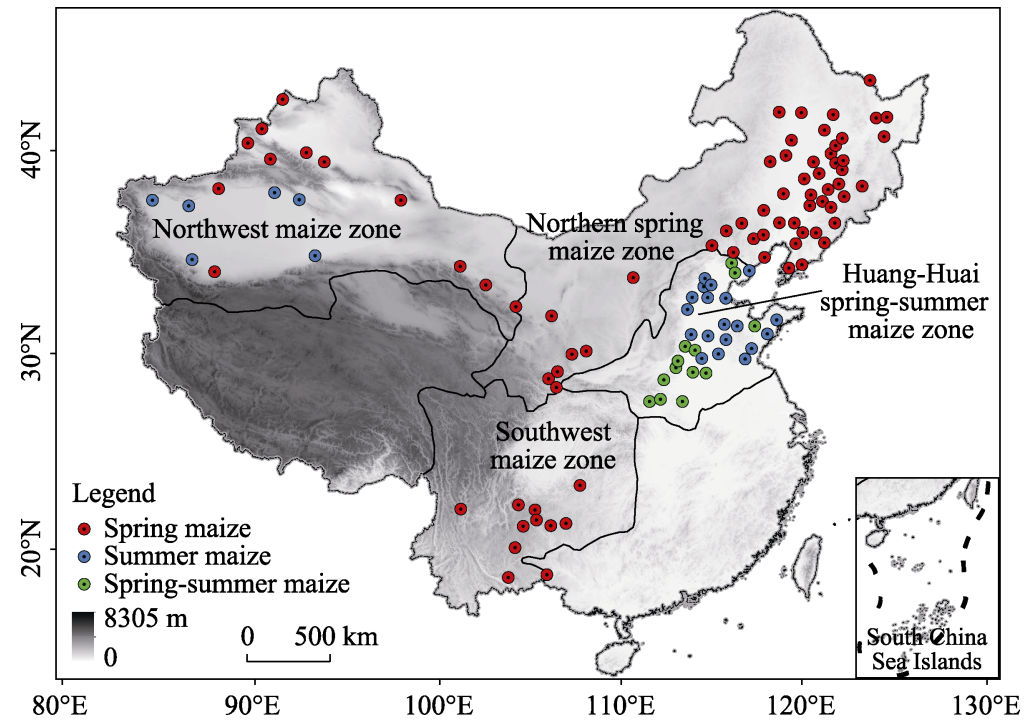

Figure 1 Spatial distribution of agro-meteorological stations of China

\subsection{Research methods}

\subsubsection{Trend analysis}

The trends observed for changes in the length of phenological stages and growth stages of maize were calculated using the following linear regression equation, considering year as the independent variable (1):

$$
\theta_{k}=\frac{n \times \sum_{i=1}^{n}\left(k \times P_{i, k}\right)-\sum_{i=1}^{n} k \times \sum_{i=1}^{n} P_{i, k}}{n \times \sum_{i=1}^{n} k^{2}-\left(\sum_{i=1}^{n} k\right)^{2}}
$$

where $n$ is the number of years in the analyzed period, $P_{i, k}$ is the length of phenological stage $k$ in year $i$ (DOY: Day of Year) or growth stage length (days) of the observation site in year $i$, $i$ represents the $i$ th year, and $\theta_{k}$ is the trend observed for changes in the length of phenological stage or growth stage $(\mathrm{d} / \mathrm{a})$. If $\theta_{k}$ is greater than 0 , it means that the length of the phenological stage or growth stage is delayed or extended, respectively; for $\theta_{k}$ lower than 0 , the length of the phenological stage or growth stage is advanced or shortened, respectively. A two-tailed $t$-test was used to evaluate the significance of the regression coefficients.

\subsubsection{Calculation of growing degree-days}

Growing degree-days (GDD) is a heat index for analyzing crop growth. In the present study, it refers to the effective GDD with a daily average air temperature $\geqslant 10^{\circ} \mathrm{C}$. It was calculated according to McMaster and Wilhelm's (1997) formula (2):

$$
G D D=\sum_{d_{s}}^{d_{e}}\left[\left(\frac{T_{\max }+T_{\min }}{2}\right)-T_{\text {base }}\right]
$$

where $d_{s}$ represents the starting date of the research phase, $d_{e}$ represents the ending date of 
the research phase, $T_{\max }$ represents the daily maximum air temperature, $T_{\min }$ represents the daily minimum air temperature, and $T_{\text {base }}$ represents the minimum biological temperature in the maize growth stage.

Based on the observed dates for phenological phases, the starting date (i.e., the date of sowing) and the ending date (i.e. the date of ripening) of maize growth were determined. Daily meteorological data were used to calculate average air temperature, precipitation, sunshine duration, and GDD during each maize growth stage at each site. Trends in average air temperature, precipitation, sunshine duration, and GDD during maize growth stages in 1981-2010 were also calculated using equation (1).

\section{Results}

\subsection{Spatio-temporal changes in climate factors}

The spatial distribution of the trends in average air temperature, precipitation, sunshine duration, and GDD changes during maize growing season at each selected site from 1981 to 2010 is shown in Figure 2. Throughout the country, average air temperature and GDD increased from 1981 to 2010 by $0.03^{\circ} \mathrm{C} / \mathrm{yr}$ and $4.92^{\circ} \mathrm{C} \mathrm{d} / \mathrm{yr}$, respectively. Precipitation and sunshine duration showed decreasing trends, and the decrease rates were $-0.16 \mathrm{~mm} / \mathrm{yr}$ and $-2.07 \mathrm{~h} / \mathrm{yr}$, respectively (Table 1). Average air temperature and GDD showed increasing trends at $90 \%$ and $83 \%$ of the selected sites, respectively, and the increase in air temperature was greater at high than at low latitudes.
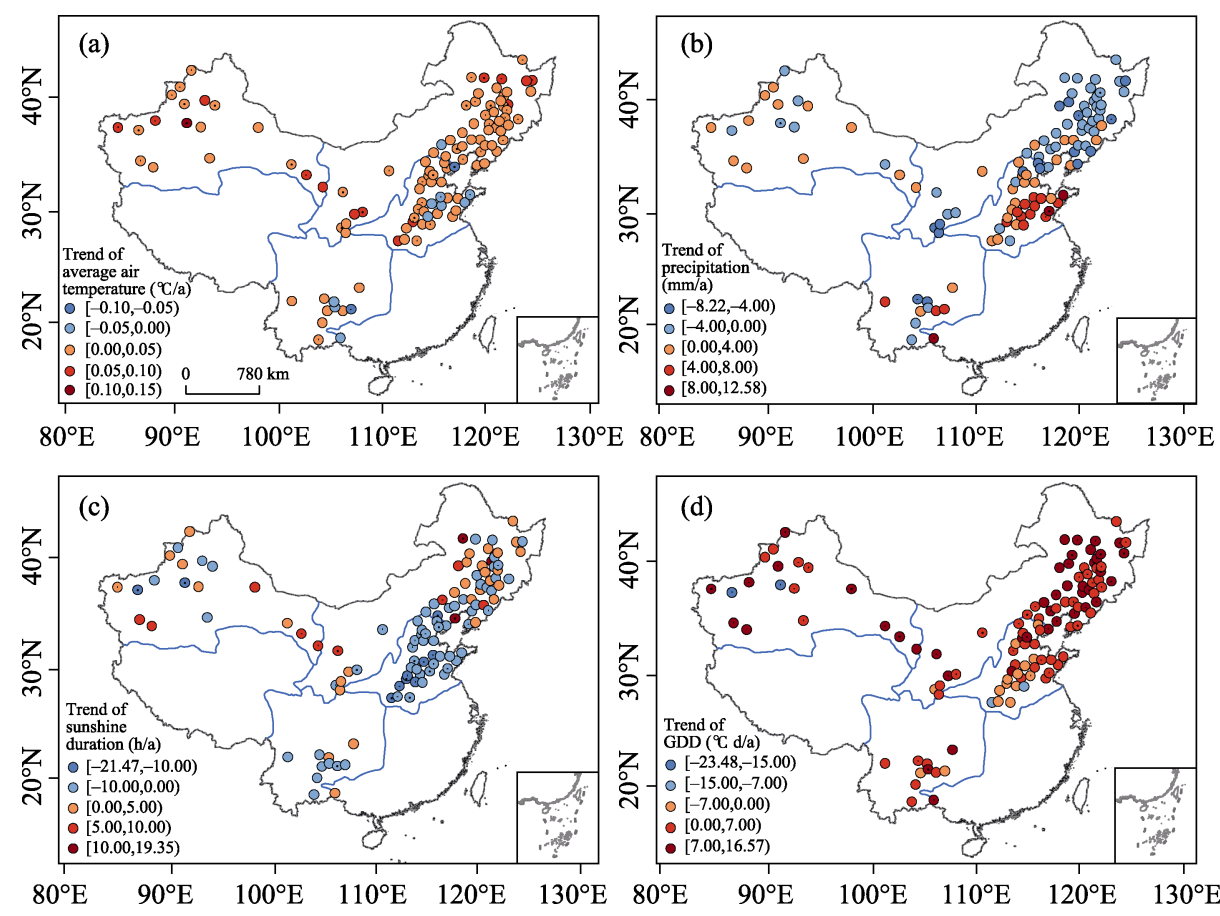

Figure 2 Spatial distribution of climate factor changing trends during the growth period of maize in China from 1981 to 2010 
Table 1 Changing trends of climate factors during the entire growth period of maize in different regions

\begin{tabular}{|c|c|c|c|c|}
\hline Growing zones & $\begin{array}{c}\text { Average air } \\
\text { temperature }\left({ }^{\circ} \mathrm{C} / \mathrm{a}\right)\end{array}$ & $\begin{array}{l}\text { Precipitation } \\
\quad(\mathrm{mm} / \mathrm{a})\end{array}$ & $\begin{array}{l}\text { Sunshine duration } \\
\text { (h/a) }\end{array}$ & $\operatorname{GDD}\left({ }^{\circ} \mathrm{C} \mathrm{d} / \mathrm{a}\right)$ \\
\hline Nationwide & $0.03 * *$ & -0.16 & $-2.07 * *$ & $4.92 * *$ \\
\hline Northwest maize zone & $0.05 * *$ & 0.14 & -0.99 & $5.26 * *$ \\
\hline $\begin{array}{l}\text { Northern spring maize } \\
\text { zone }\end{array}$ & $0.04 * *$ & $-2.26 * *$ & 0.51 & $7.01 * *$ \\
\hline $\begin{array}{l}\text { Huang-Huai } \\
\text { spring-summer maize } \\
\text { zone }\end{array}$ & $0.02 * *$ & $2.61 * *$ & $-7.30 * *$ & 0.87 \\
\hline Southwest maize zone & -0.001 & 1.53 & -1.15 & $5.81 * *$ \\
\hline
\end{tabular}

Note: "+" and "-" indicate that the climate factor increased or decreased, ** and * indicate significance levels at 0.01 or 0.05 respectively.

Precipitation showed obvious regional differences (Figure $2 b$ ). In most zones, precipitation showed a decreasing trend (55\%), especially in northern spring maize zone, northwest maize zone, and southwest maize zone; however, precipitation in the Huang-Huai spring-summer maize zone showed an increasing trend. In terms of planting type, precipitation decreased by $1.30 \mathrm{~mm} / \mathrm{yr}$ during the spring breeding growth stage of maize, while during the growth stage of summer maize and spring-summer maize it increased by $2.49 \mathrm{~mm} / \mathrm{yr}$ and $1.44 \mathrm{~mm} / \mathrm{yr}$, respectively. Sunshine duration decreased by $63 \%$ of the selected sites, but it was most significant in the Huang-Huai spring-summer maize zone, showing a decrease of $-7.30 \mathrm{~h} / \mathrm{yr}$ (Figure 2c and Table 1); on the contrary, sunshine duration in the northern spring maize zone showed an increasing trend of $0.51 \mathrm{~h} / \mathrm{yr}$ (Table 1). On average, sunshine duration during the growing season of spring maize was $0.31 \mathrm{~h} / \mathrm{yr}$, and $-5.37 \mathrm{~h} / \mathrm{yr}$ and $-10.03 \mathrm{~h} / \mathrm{yr}$ during the growing season of summer and spring-summer maize, respectively.

\subsection{Spatio-temporal changes in the phenological stages of maize}

The phenological stages of maize were mainly delayed nationwide, at $68 \%, 54 \%, 53 \%, 54 \%$, $55 \%, 74 \%$, and $77 \%$ of the sites showing a delaying trend in the sowing, seedling, three-leaf, jointing, tasseling, milk-ripe, and ripening dates, respectively. However, 54\% of the sites showed an advancing trend in the seven-leaf stage. Sites with delayed sowing, seedling, three-leaf, jointing, and tasseling dates were mainly distributed across the Huang-Huai spring-summer maize zone, although there were some sites in the eastern part of the northern spring maize zone and in the northwest maize zone. Sites where the seven-leaf stage tended to advance were mainly located in the southeast of the northern spring maize zone (Figure 3d).

There was a significant inter-regional difference in the changes observed in maize phenological stages (Figure 3 and Table 2). Within the same zone, the phenological phases were significantly different for different maize planting types. In the northwest maize zone, spring maize showed an advancing trend from the sowing to the jointing date $(0.05<\theta<0.24$ $\mathrm{d} / \mathrm{yr}$ ), while the tasseling, milk-ripe, and ripening dates were delayed by $0.02,0.12$, and 0.06 $\mathrm{d} / \mathrm{yr}$; all phenological phases of summer maize, from sowing to ripening date, were delayed $(0.21<\theta<0.87 \mathrm{~d} / \mathrm{yr})$. All phenological phases of spring maize in the southwest maize zone were advanced $(0.13<\theta<0.53 \mathrm{~d} / \mathrm{yr})$. In contrast, the phenological phases of spring maize in northern China were mainly delayed $(0.01<\theta<0.30 \mathrm{~d} / \mathrm{yr})$, as only the seven-leaf stage was 
advanced $(-0.14 \mathrm{~d} / \mathrm{yr})$. In the Huang-Huai spring-summer maize zone, the phenological phases of summer maize were delayed from the sowing to the ripening date $(0.09<\theta<0.35$ $\mathrm{d} / \mathrm{yr}$ ). The phenological phases of spring-summer maize were also delayed, and sowing data had a significant delay $(0.96 \mathrm{~d} / \mathrm{yr})$; the sowing date of spring-summer maize was significantly delayed, resulting in the shortening of the entire growth stage. Due to the implementation
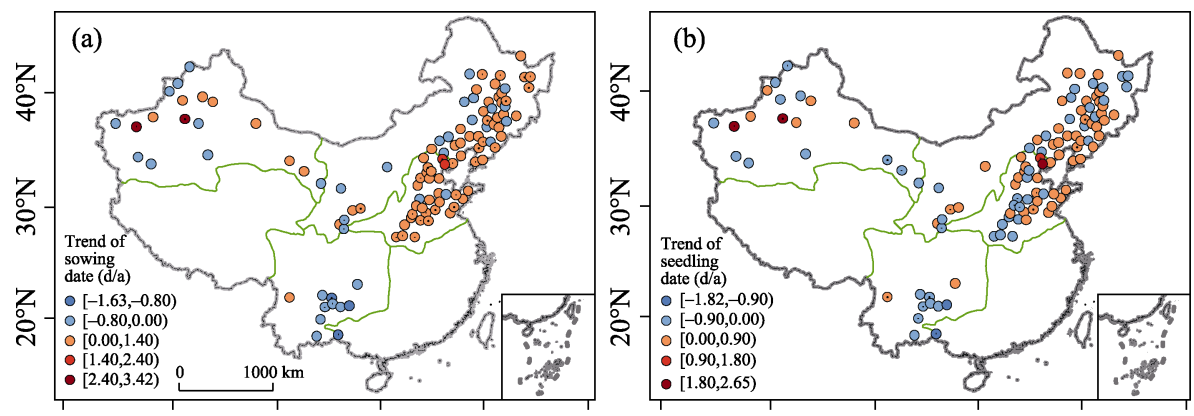

$80^{\circ} \mathrm{E} \quad 90^{\circ} \mathrm{E} \quad 100^{\circ} \mathrm{E} \quad 110^{\circ} \mathrm{E} \quad 120^{\circ} \mathrm{E} \quad 130^{\circ} \mathrm{E} \quad 80^{\circ} \mathrm{E}$
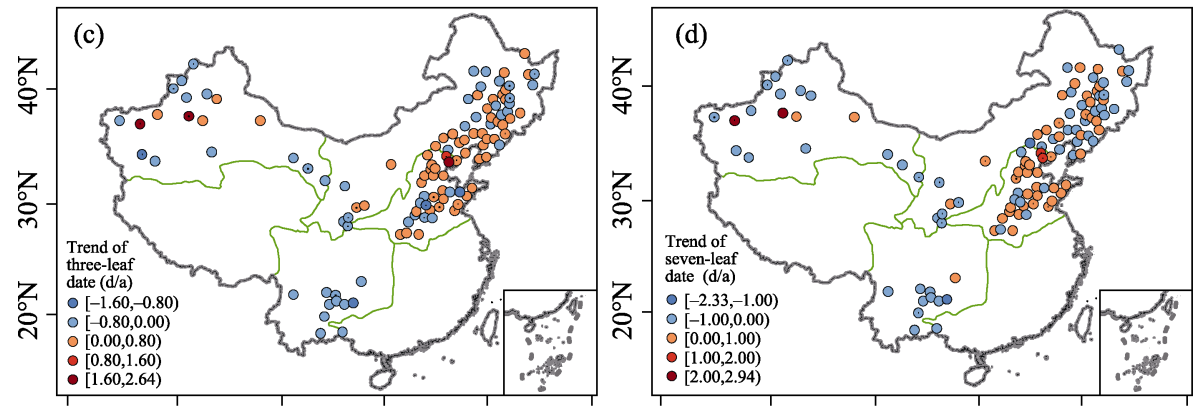

$80^{\circ} \mathrm{E} \quad 90^{\circ} \mathrm{E} \quad 100^{\circ} \mathrm{E} \quad 110^{\circ} \mathrm{E} \quad 120^{\circ} \mathrm{E} \quad 130^{\circ} \mathrm{E}$
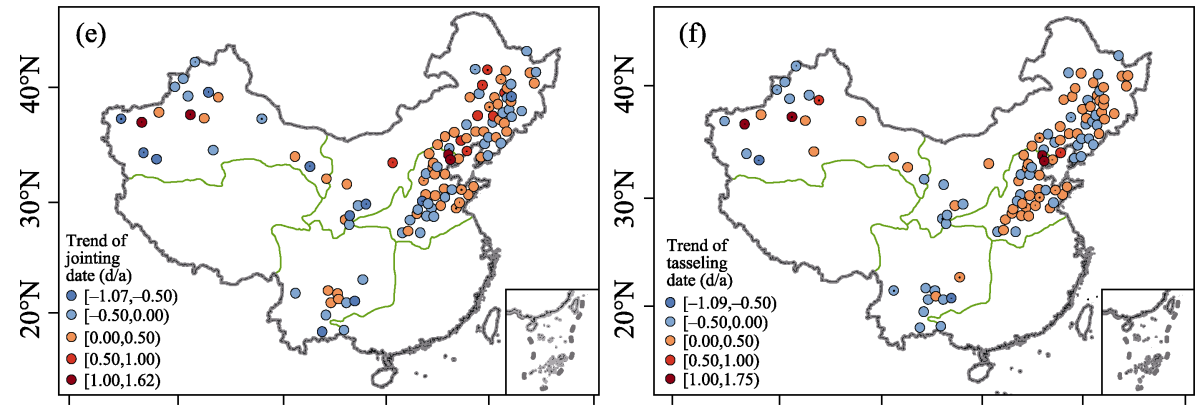

$80^{\circ} \mathrm{E} \quad 90^{\circ} \mathrm{E} \quad 100^{\circ} \mathrm{E} \quad 110^{\circ} \mathrm{E} \quad 120^{\circ} \mathrm{E} \quad 130^{\circ} \mathrm{E} \quad 80^{\circ} \mathrm{E}$
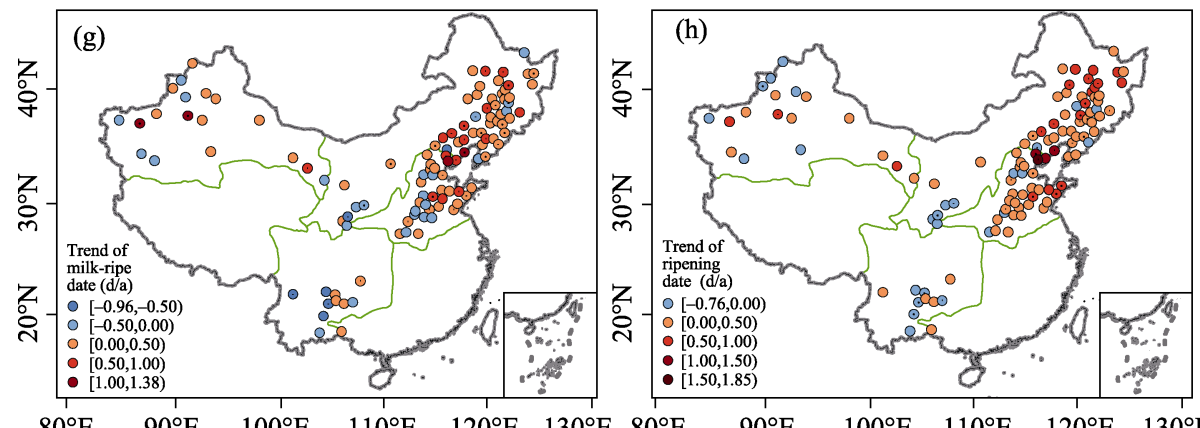

Figure 3 Spatial distribution of maize phenological trends in China from 1981 to 2010 
Table 2 Changing trend of major phenological/growing stages length of maize in different regions from 1981 to $2010(\mathrm{~d} / \mathrm{yr})$

\begin{tabular}{|c|c|c|c|c|c|c|c|c|c|c|c|c|}
\hline $\begin{array}{c}\text { Growing } \\
\text { zones }\end{array}$ & $\begin{array}{c}\text { Planting } \\
\text { type }\end{array}$ & $\begin{array}{c}\text { Sowing } \\
\text { date }\end{array}$ & $\begin{array}{l}\text { Seed- } \\
\text { ling } \\
\text { date }\end{array}$ & $\begin{array}{c}\text { Three-1 } \\
\text { eaf } \\
\text { date }\end{array}$ & $\begin{array}{l}\text { Seven- } \\
\text { leaf } \\
\text { date }\end{array}$ & $\begin{array}{l}\text { Joint- } \\
\text { ing } \\
\text { date }\end{array}$ & $\begin{array}{l}\text { Tas- } \\
\text { seling } \\
\text { date }\end{array}$ & $\begin{array}{c}\text { Milk-rip } \\
\text { e date }\end{array}$ & $\begin{array}{l}\text { Ripen- } \\
\text { ing date }\end{array}$ & $\begin{array}{l}\text { Vegeta- } \\
\text { tive } \\
\text { growth } \\
\text { stage }\end{array}$ & $\begin{array}{l}\text { Repro- } \\
\text { ductive } \\
\text { growth } \\
\text { stage }\end{array}$ & $\begin{array}{c}\text { Entire } \\
\text { growth } \\
\text { stage }\end{array}$ \\
\hline \multirow[b]{2}{*}{$\begin{array}{l}\text { Northwest } \\
\text { maize zone }\end{array}$} & $\begin{array}{l}\text { Spring } \\
\text { maize }\end{array}$ & -0.05 & -0.20 ** & $-0.16^{*}$ & $-0.24 * *$ & $-0.18 * *$ & 0.02 & 0.12 & 0.06 & $0.02 *$ & 0.03 & 0.10 \\
\hline & $\begin{array}{l}\text { Sum- } \\
\text { mer } \\
\text { maize }\end{array}$ & $0.87 * *$ & $0.66^{* *}$ & $0.64 * *$ & $0.73^{* *}$ & 0.21 & $0.46^{* *}$ & $0.39^{* *}$ & $0.22 *$ & -0.46 & $-0.24 * *$ & $-0.65^{* *}$ \\
\hline $\begin{array}{l}\text { Northern spring } \\
\text { maize zone }\end{array}$ & $\begin{array}{l}\text { Spring } \\
\text { maize }\end{array}$ & $0.18^{* *}$ & 0.04 & 0.01 & $-0.14 * *$ & $0.10^{* *}$ & $0.05^{*}$ & $0.23 * *$ & $0.30^{* *}$ & -0.12 & $0.25^{* *}$ & $0.11 * *$ \\
\hline $\begin{array}{l}\text { Huang-Huai } \\
\text { spring-summer } \\
\text { maize zone }\end{array}$ & $\begin{array}{l}\text { Spring } \\
\text { maize }\end{array}$ & $-0.52 * *$ & $-0.53 * *$ & $-0.45^{* *}$ & $-0.32 * *$ & $-0.24 *$ & $-0.24 *$ & -0.13 & -0.18 & $0.35^{* *}$ & 0.10 & $0.41 * *$ \\
\hline \multirow{2}{*}{$\begin{array}{l}\text { Southwest } \\
\text { maize zone }\end{array}$} & $\begin{array}{l}\text { Sum- } \\
\text { mer } \\
\text { maize }\end{array}$ & $0.20 * *$ & $0.17 * *$ & $0.22 * *$ & $0.15^{* *}$ & $0.09 *$ & $0.09^{*}$ & $0.25 * *$ & $0 . .35 * *$ & $-0.11 *$ & $0.26 * *$ & $0.14 * *$ \\
\hline & $\begin{array}{l}\text { Spring- } \\
\text { summer } \\
\text { maize }\end{array}$ & $0.96^{* *}$ & $0.17 * *$ & 0.13 & $0.18^{*}$ & $0.12 *$ & $0.23 * *$ & $0.22 * *$ & $0.37^{* *}$ & -0.83 & $0.14^{*}$ & $-0.60 * *$ \\
\hline
\end{tabular}

Note: "+" indicates the phenology / growing stages length delayed or prolonged; "-_ indicates the phenological / growing stages length advanced or shortened. $* *$ and $*$ indicate significance levels at 0.01 or 0.05 respectively.

of the intermittent growth system comprising spring maize, winter wheat, and summer maize in this zone, the sowing date of maize was affected not only by climate factors but also by the planting and harvesting time of the previous seasonal crop.

Different growing zones also presented significant differences in the direction and magnitude of the trends observed for changes in the phenological phases of maize of the same planting type. For instance, the phenological phases of spring maize were mainly advanced in the southwest maize zone, but mainly delayed in the northern spring maize zone. The delay in the phenological phases in the northwest maize zone $(0.21<\theta<0.87 \mathrm{~d} / \mathrm{yr})$ was significantly greater than the delay of the phenological phases of summer maize in the Huang-Huai spring-summer maize zone $(0.09<\theta<0.35 \mathrm{~d} / \mathrm{yr})$.

\subsection{Changes in the length of key growth stages}

Maize vegetative growth, reproductive growth, and entire growth stages were extended at $34 \%, 71 \%$, and $57 \%$ of the selected sites, respectively, with extension ranges of $0.08-0.76$, $0.61-0.97$, and $0.03-1.07 \mathrm{~d} / \mathrm{yr}$, respectively. On average, the vegetative growth stage of spring maize was shortened by $0.06 \mathrm{~d} / \mathrm{yr}$. Reproductive growth and entire growth stages were extended by $0.18 \mathrm{~d} / \mathrm{yr}$ and $0.16 \mathrm{~d} / \mathrm{yr}$, respectively. Spring maize in the northwest maize zone and southwest maize zone showed an extension trend at the three growth stages. The vegetative growth stage of spring maize in the northern spring maize zone was shortened, while reproductive growth and entire growth stages were mainly extended (Table 2). The vegetative growth and entire growth stages of summer maize were shortened by $0.20 \mathrm{~d} / \mathrm{yr}$ and $0.05 \mathrm{~d} / \mathrm{yr}$, respectively. The reproductive growth stage was extended by $0.14 \mathrm{~d} / \mathrm{yr}$. The three growth stages of summer maize were shortened in the northwest maize zone, while vegetative growth stage was shortened in the Huang-Huai spring-summer maize zone; re- 
productive and entire growth stages of this maize type were extended in the Huang-Huai spring-summer maize zone (Table 2). The reproductive growth stage of spring-summer maize in the Huang-Huai spring-summer maize zone was extended $(0.14 \mathrm{~d} / \mathrm{yr})$, but vegetative and entire growth stages were shortened by $0.83 \mathrm{~d} / \mathrm{yr}$ and $0.60 \mathrm{~d} / \mathrm{yr}$, respectively (Figure 4).

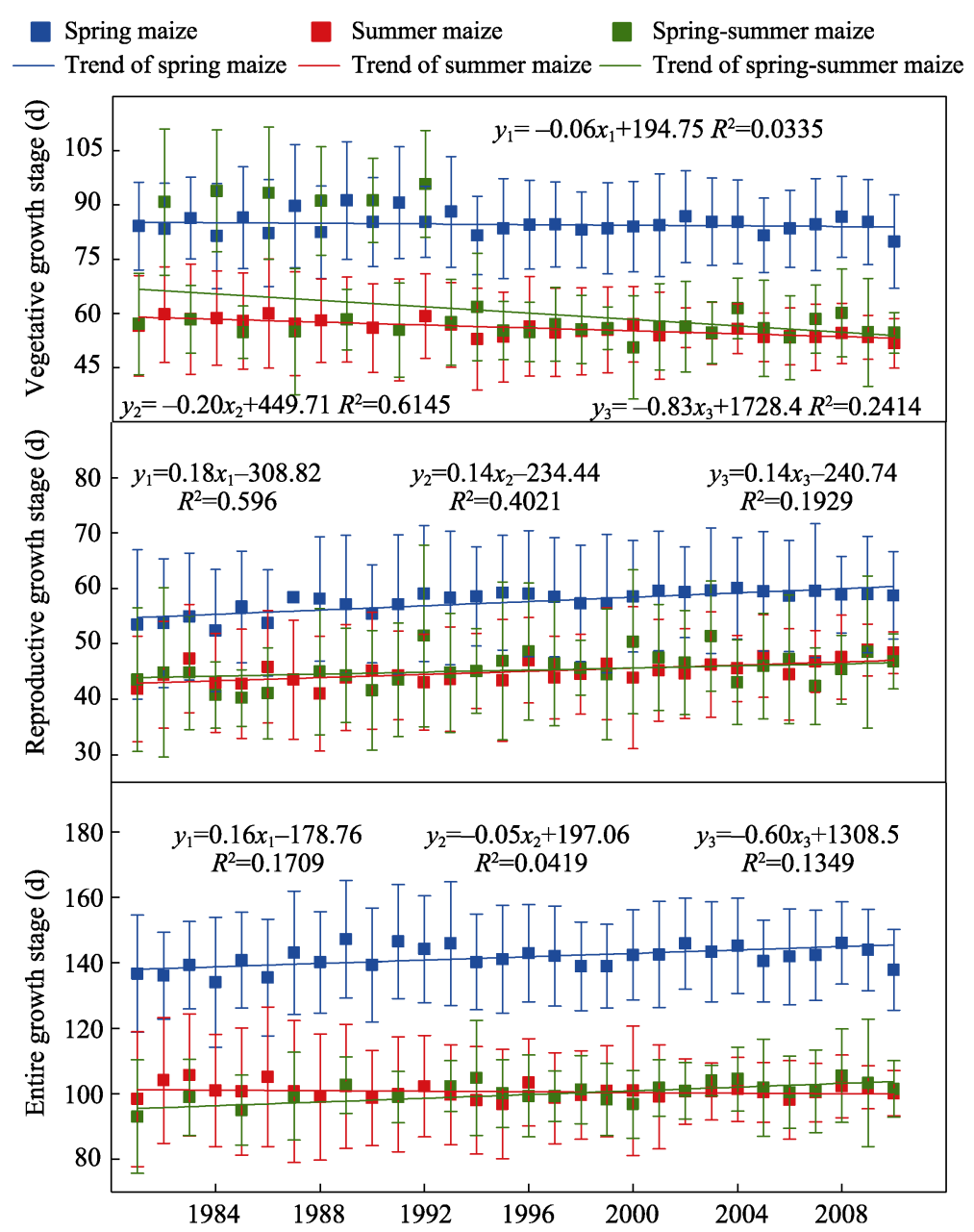

Figure 4 Trends of three growing stages length of different planting types of maize from 1981 to 2010

\section{Discussion}

From 1981 to 2010, the average air temperature increased during the growth stage of spring, summer, and spring-summer maize in China $\left(0.03,0.02\right.$, and $0.05{ }^{\circ} \mathrm{C} / \mathrm{yr}$, respectively). In general, elevated air temperatures affect all stages of crop growth and development, including seedling, flowering, and ripening (Liu et al., 2010; Hou et al., 2014; Liu et al., 2017). For progressing from one growth stage to the next, crops need to accumulate enough effective accumulated temperature. Thus, an increase in air temperature can accelerate the accumulation of effective accumulated temperature and shorten each growth stage (Zhang et al., 2013; Zhang et al., 2018), leading to earlier phenological phases or shorter growth stages (Vitasse et al., 2011; Liu et al., 2018b). Precipitation and sunshine duration can also affect crop growth. According to our results, except for the slight decrease in average air temperature 
$\left(-0.001{ }^{\circ} \mathrm{C} / \mathrm{yr}\right)$ during the maize growth stage in the southwest maize zone, average air temperature and GDD in the four maize zones showed an increasing trend, whereas precipitation and sunshine duration showed mainly increasing and decreasing trends, respectively. The phenological phases of spring maize in China mainly advanced in the past 30 years. For example, phenological phases from the sowing date to the jointing date were advanced $(0.05<\theta<0.24 \mathrm{~d} / \mathrm{yr})$ in the northwest maize zone. The vegetative, reproductive, and entire growth stages in this zone were extended by $0.02,0.03$, and $0.10 \mathrm{~d} / \mathrm{yr}$, respectively, which is consistent with the findings of Xiao et al. (2015). The phenological stages of spring maize from seeding to maturation were advanced in the southwest maize zone $(0.13<\theta<0.53 \mathrm{~d} / \mathrm{yr})$, however, in the northern spring maize zone, the seven-leaf date showed an advancing trend $(-0.14 \mathrm{~d} / \mathrm{yr})$; sowing, seedling, and ripening dates were delayed by $0.18,0.04$, and $0.30 \mathrm{~d} / \mathrm{yr}$, respectively. This is consistent with the findings of Li et al. (2009). From 1961 to 2010, the air temperature during the maize breeding growth stage in northeast farming areas increased significantly (Yin et al., 2015). Since 1991, the precipitation in the maize growing season (April-September) continued to decrease in northeast China. Since 1971, the accumulated temperature $\geq 10^{\circ} \mathrm{C}$ in this area has increased by $262.8^{\circ} \mathrm{C}$, and the accumulated temperature $\geq 10^{\circ} \mathrm{C}$ (at $2700^{\circ} \mathrm{C}$ for example) has shifted about $200-300 \mathrm{~km}$ to the north and $50-150 \mathrm{~km}$ to the east (Ji et al., 2012). The northeast region is dominated by the planting of spring maize, and changes in climate factors during the maize growth stage are similar to the spatial variations of climatic factors observed for northeast spring maize in the northern spring maize zone. Accordingly, the three provinces in northeast China showed an advanced seedling date $(0.02<\theta<0.15 \mathrm{~d} / \mathrm{yr})$ and a delayed ripening date $(0.18<\theta<0.38 \mathrm{~d} / \mathrm{yr})$ for spring maize from 1990 to 2009 (Li et al., 2013). Liu et al. (2013) also reported that the sowing date in northeast China was advanced from 1981 to 2007, while the ripening date was delayed. Nationwide, the vegetative growth stage was shortened $(-0.06 \mathrm{~d} / \mathrm{yr})$, while the reproductive and entire growth stages of spring maize were extended (by 0.18 and $0.16 \mathrm{~d} / \mathrm{yr}$, respectively). Summer maize and spring-summer maize showed a delaying trend in the phenological stages until the ripening stage. Whereas, due to the influence of local regional climate, the differences among regions were significant (Figure 3 and Table 2). The growth stages of summer maize in the northwest maize zone and spring-summer maize in Huang-Huai spring-summer maize zone were shortened ( -0.65 and $-0.60 \mathrm{~d} / \mathrm{yr}$, respectively), while the growth stage of summer maize in Huang-Huai spring-summer maize zone was extended $(0.14 \mathrm{~d} / \mathrm{yr})$. Previous studies have found that during the growth stage of the summer maize in the North China Plain, air temperature decreased with latitude, sunshine duration declined significantly, and the number of days in the entire growth stage increased significantly from 1981 to 2009 (Meng et al., 2015). Our results for the changes in sunshine duration in the growth stage in Huang-Huai spring-summer maize zone are consistent with these findings. Therefore, the decrease in sunshine duration might be an important factor for extending maize growth season.

Many studies have examined spatio-temporal differences in changes in maize phenology and in the duration of each growth stage in China under different climate change scenarios. However, the effects of human activity such as cultivar shifts, use of fertilizers, and irrigation on crop phenology still need further investigation. Thus, combined crop models including the effect of climate changes, management measures, and other variables that might affect crop growth, should be considered in future studies. Changes in the length of each 
growth stage of maize are caused by changes in the corresponding phenological phases; therefore, discussing changes in maize phenological stages and growth stages at different scales, such as site, regional, and inter-regional levels, and including different planting types could help gain insight into the effects of climate change on crop phenology.

\section{Conclusions}

(1) During the past three decades (1981-2010), there were significant changes in maize phenological phases of China. While the phenological phases of spring maize were mainly advanced, those of summer maize showed a delaying trend in different regions. Specifically, sowing to jointing dates of spring maize in the northwest maize zone were advanced $(0.05<\theta<0.24 \mathrm{~d} / \mathrm{yr})$, as well as sowing to ripening dates in the southwest maize zone $(0.13<\theta<0.53 \mathrm{~d} / \mathrm{yr})$. Spring maize in the northern spring maize zone only advanced at the seven-leaf stage $(0.14 \mathrm{~d} / \mathrm{yr})$. The delayed range of summer maize phenological phases in the northwest maize zone $(0.21<\theta<0.87 \mathrm{~d} / \mathrm{yr})$ was generally greater than in the Huang-Huai spring-summer maize zone $(0.09<\theta<0.35 \mathrm{~d} / \mathrm{yr})$.

(2) All phenological stages of spring and summer maize in Huang-Huai spring-summer maize zone showed a delaying trend $(0.12<\theta<0.96 \mathrm{~d} / \mathrm{yr})$. The changes in the phenological phases resulted in changes in the length of the corresponding growth stage. The vegetative growth stage of spring maize showed a shortening trend $(-0.06 \mathrm{~d} / \mathrm{yr})$, and the reproductive growth and entire growth stages showed an extending trend ( 0.18 and $0.16 \mathrm{~d} / \mathrm{yr}$, respectively).

(3) The vegetative growth $(-0.20 /-0.83 \mathrm{~d} / \mathrm{yr})$ and entire growth $(-0.05 /-0.60 \mathrm{~d} / \mathrm{yr})$ stages of summer and spring-summer maize were shortened, while their reproductive growth stages were extended $(0.14 / 0.14 \mathrm{~d} / \mathrm{yr})$. In general, the phenological phases of spring maize in China were advanced, while the phenological phases of summer and spring-summer were delayed; the length of each growth stage was mainly extended in different regions.

\section{References}

Cui L L, Shi J, Ma Y et al., 2018. Variations of the thermal growing season during the period 1961-2015 in northern China. Journal of Arid Land, 10(2): 264-276.

Fu G, Zhong Z M, 2016. Initial response of phenology and aboveground biomass to experimental warming in a maize system of the Tibet. Ecology and Environmental Sciences, 25(7): 1093-1097. (in Chinese)

Guo J P, 2015. Advances in impacts of climate change on agricultural production in China. Journal of Applied Meteorological Science, 26(1): 1-11. (in Chinese)

He L, Asseng S, Zhao G et al., 2015. Impacts of recent climate warming, cultivar changes, and crop management on winter wheat phenology across the Loess Plateau of China. Agricultural and Forest Meteorology, 200: 135-143.

Hou P, Liu Y E, Xie R Z et al., 2014. Temporal and spatial variation in accumulated temperature requirements of maize. Field Crops Research, 158: 55-64.

IPCC, 2014. Climate change 2014: The physical science basis. Contribution of Working Group 1 to the Fifth Assessment Report of the Intergovernmental Panel on Climate Change. Cambridge: Cambridge University Press, 5-7.

Ji R P, Zhang Y S, Jiang L X et al., 2012. Effect of climate change on maize production in Northeast China. Geographical Research, 31(2): 290-298. (in Chinese)

Li R P, Zhou G S, Shi K Q et al., 2009. Phenological characteristics of maize and their response to the climate from 1980 to 2005. Journal of Anhui Agricultural Science, 37(31): 15197-15199, 15267. (in Chinese)

Li Z G, Yang P, Tang H J et al., 2013. Trends of spring maize phenophases and spatio-temporal responses to temperature in three provinces of Northeast China during the past 20 years. Acta Ecologica Sinica, 33(18): 
5818-5827. (in Chinese)

Liu Y, Wang E L, Yang X G et al., 2010. Contributions of climatic and crop varietal changes to crop production in the North China Plain, since 1980s. Global Change Biology, 16(8): 2287-2299.

Liu Y J, Chen Q M, Ge Q S et al., 2018a. Modelling the impacts of climate change and crop management on phenological trends of spring and winter wheat in China. Agricultural and Forest Meteorology, 248: 518-526.

Liu Y J, Chen Q M, Ge Q S et al., 2018b. Spatiotemporal differentiation of changes in wheat phenology in China under climate change from 1981 to 2010. Science China-Earth Sciences, 61: 1088-1097.

Liu Y J, Qin Y, Ge Q S et al., 2017. Reponses and sensitivities of maize phenology to climate change from 1981 to 2009 in Henan Province, China. Journal of Geographical Sciences, 27(9): 1072-1084.

Liu Z J, Hubbard Kenneth G, Lin X M et al., 2013. Negative effects of climate warming on maize yield are reversed by the changing of sowing date and cultivar selection in Northeast China. Global Change Biology, 19(11): 3481-3492.

McMaster G S, Wilhelm W W, 1997. Growing degree-days: One equation, two interpretations. Agricultural and Forest Meteorology, 87(4): 291-300.

Meng L, Liu X J, Wu D R et al., 2015. Responses of summer maize main phenology to climate change in the North China Plain. Chinese Journal of Agrometeorology, 36(4): 375-382. (in Chinese)

Sacks William J, Kucharik Christopher J, 2011. Crop management and phenology trends in the US Corn Belt: Impacts on yields, evapotranspiration and energy balance. Agricultural and Forest Meteorology, 151(7): 882-894.

Tao F L, Zhang S, Zhang Z et al., 2014. Maize growing duration was prolonged across China in the past three decades under the combined effects of temperature, agronomic management, and cultivar shift. Global Change Biology, 20(12): 3686-3699.

Tong P Y, 1992. Maize planting regionalization in China. Beijing: Press of Chinese Agriculture Science and Technology, 6-24. (in Chinese)

Vitasse Y, Francois C, Delpierre N et al., 2011. Assessing the effects of climate change on the phenology of European temperate trees. Agricultural and Forest Meteorology, 151(7): 969-980.

Wang L X, Chen H L, Li Q et al., 2010 Research advances in plant phenology and climate. Acta Ecologica Sinica, 30(2): 447-454. (in Chinese)

Wang N, Wang J, Wang E L et al., 2015. Increased uncertainty in simulated maize phenology with more frequent supra-optimal temperature under climate warming. European Journal of Agronomy, 71: 19-33.

Xiao D P, 2015. Changes of crop phenology in Inner Mongolia under the background of climate warming. Chinese Agricultural Science Bulletin, 31(26): 216-221. (in Chinese)

Yin X G, Wang M, Kong Q X et al., 2015. Impacts of high temperature on maize production and adaptation measures in Northeast China. Chinese Journal of Applied Ecology, 26(1): 186-198. (in Chinese)

Zhao J, Yang X G, Dai S W et al., 2015. Increased utilization of lengthening growing season and warming temperatures by adjusting sowing dates and cultivar selection for spring maize in Northeast China. European Journal of Agronomy, 67: 12-19.

Zhang T Y, Huang Y, Yang X G, 2013. Climate warming over the past three decades has shortened rice growth duration in China and cultivar shifts have further accelerated the process for late rice. Global Change Biology, 19(2): 563-570.

Zhang W X, Liu P X, Feng Q R et al., 2018. The spatiotemporal responses of Populus euphratica to global warming in Chinese oases between 1960 and 2015. Journal of Geographical Sciences, 28(5): 579-594.

Zheng J Y, Ge Q S, Hao Z X, 2002. Impacts of climate warming on plants phenophases in China for the last 40 years. Chinese Science Bulletin, 47(21): 1826-1831.

Zheng J Y, Ge Q S, Hao Z X et al., 2012. Changes of spring phenodate in Yangtze River Delta region in the past 150 years. Acta Geographica Sinica, 67(1): 45-52. (in Chinese) 